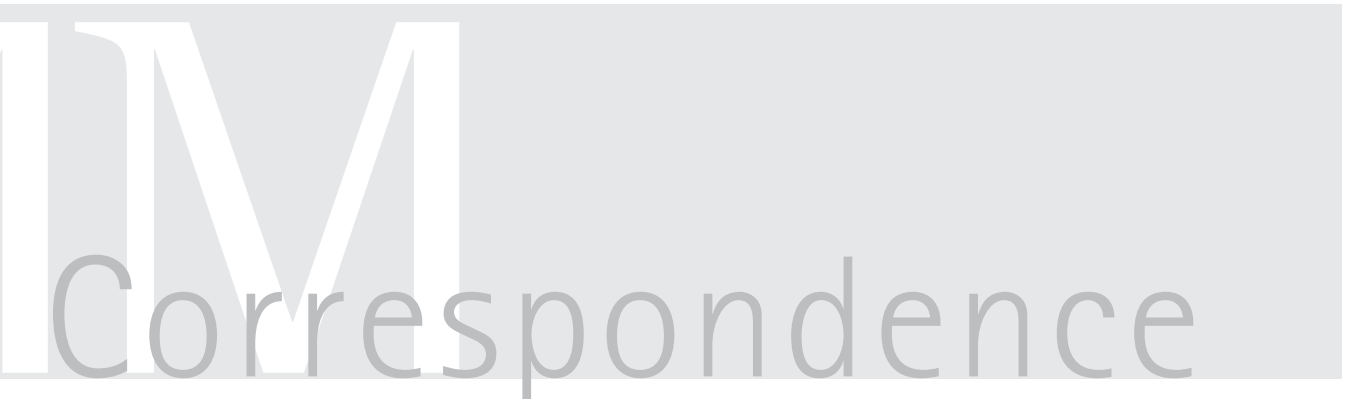

\title{
Plasmid-borne extended-spectrum $\beta$-lactamase in a clinical isolate of Acinetobacter baumannii
}

Acinetobacter baumannii has emerged over the last decade as a significant opportunistic pathogen. Although it is generally associated with benign colonization of hospitalized patients, it is responsible for about $10 \%$ of nosocomial infection in intensive care unit (ICU) patients, causing a wide range of infections such as bacteraemia, nosocomial pneumonia, urinary tract infection, secondary meningitis and burn and wound infections (Bergogne-Berezin, 2001; Joshi, 1998; Levin et al., 2003; Poirel et al., 1999). In Acinetobacter-associated nosocomial infection, the major problem encountered by ICU clinicians relates to the readily transferable antimicrobial resistance expressed by this organism (BergogneBerezin, 2001; Joshi, 1998). In addition to intrinsic resistance, $A$. baumannii has the ability to acquire resistance to many major classes of antibiotics including newer $\beta$ lactams (Perilli et al., 1996). The presence of resistance plasmids (R-plasmids) is a significant feature of this organism, and plasmid profiling has been proposed as a method of epidemiological typing for Acinetobacter (Joshi, 1998; Perilli et al., 1996). Although A. baumannii colonizes hospitalized patients, approximately $30 \%$ of isolates are associated with frank infection in ICU patients and, in this setting, tend to demonstrate variable susceptibility profiles (Dy et al., 1999). Nevertheless, despite the rising clinical importance of $A$. baumannii compared with other nosocomial pathogens in developing countries, this organism has been widely overlooked. In this study, five isolates of $A$. baumannii isolated in 1998 from exudates of post-surgical wound sepsis from our teaching hospital were examined. The isolates were found to harbour transferable extended-spectrum $\beta$-lactamase (ESBL)encoding resistance determinants on a $66 \cdot 1 \mathrm{~kb}$ conjugative plasmid.

The isolates were identified (Von Graevenitz, 1995) and biotyped according to the method of Bouvet \& Grimont (1987). Escherichia coli DH5 $\alpha$ was used as the recipient strain for bacterial conjugation experiments. The size of the test plasmid was estimated using E. coli NCTC 50192 carrying plasmids of $154,66 \cdot 1,37 \cdot 6$ and $7 \cdot 7 \mathrm{~kb}$.

Antimicrobial susceptibility testing of clinical isolates of A. baumannii, E. coli transconjugants and their plasmid-cured derivatives was first performed by the discdiffusion technique (Hi-Media). The MIC of the isolates was determined according to NCCLS guidelines (NCCLS, 1997). E. coli ATCC 25922 was included as a control strain for susceptibility testing. The antibiotics tested are listed in Table 1. ESBL production was confirmed by using a double-disc synergy (DDS) test, which was performed by placing a cetazidime disc (30 $\mu \mathrm{g})$ or a cefotaxime disc $(30 \mu \mathrm{g}) 30 \mathrm{~mm}$ away from a disc containing amoxycillin/ clavulanate $(60 / 10 \mu \mathrm{g})$, as described previously (Jarlier et al., 1988). ESBL production was considered positive when an enhanced zone of inhibition was visible between the $\beta$-lactam- and $\beta$-lactamase inhibitor-containing disks.

Plasmid DNA was isolated by the alkaline lysis method, separated by electrophoresis on $0.7 \%(\mathrm{w} / \mathrm{v})$ agarose gels using TBE buffer and stained with ethidium bromide as described by Sambrook et al. (1989).

Bacterial conjugation experiments were performed by the membrane filter mating technique (Willets, 1988). An initial donorto-recipient ratio of $1: 20$ was used for mating. Mueller-Hinton agar plates containing rifampicin $\left(300 \mu \mathrm{g} \mathrm{ml}^{-1}\right)$ plus ceftazidime ( $50 \mu \mathrm{g} \mathrm{ml}^{-1}$ ) were used for selection of transconjugants. For each conjugation experiment, the plasmid profiles and antibiograms of five randomly selected transconjugants were analysed for the presence of plasmid DNA and cotransfer of resistance determinants. The transconjugation frequency was calculated as the number of transconjugants per donor viable cell counts. Curing of plasmidencoded antibiotic-resistance determinants from both the donor and transconjugant was carried out using ethidium bromide $\left(10-512 \mu \mathrm{g} \mathrm{ml}^{-1}\right)$ as described previously (Stanisich, 1988) and the plasmid profiles of derivatives were analysed at various concentrations of curing agent during growth to determine optimal plasmid curing. The growth cycles were repeated five times to ensure plasmid curing and antibiograms and MICs were determined each time to correlate curing of plasmid with resistance determinants in cured derivatives. All experiments were repeated at least three times and were highly reproducible.

During analysis, all five isolates of $A$. baumannii were identified as biotype 9 and were found to express resistance to routine $\beta$-lactams tested in our laboratory. Table 1 shows MIC values of various $\beta$-lactams in the A. baumannii isolates, E. coli DH5 $\alpha$ transconjugants and their plasmid-cured derivatives. The isolates were positive for production of ESBL activity when tested by a positive DDS test with ceftazidime or cefotaxime (Table 1). The plasmid profiles appeared to be similar for all isolates, with plasmid sizes estimated to be approximately $66 \cdot 1,18 \cdot 1$ and $5 \cdot 2 \mathrm{~kb}$ (Fig. 1). Curing of plasmids by ethidium bromide at a subinhibitory concentration of $512 \mu \mathrm{g} \mathrm{ml}^{-1}$ was highly efficient. The disappearance of antibiotic resistance to expanded-spectrum cephalosporins with the concurrent loss of all three plasmids from all A. baumannii isolates suggested that the ESBL determinants were plasmid-borne.

During mating experiments with E. coli $\mathrm{DH} 5 \alpha$, conjugational transfer of the ESBLencoding determinant found to be present on a $66 \cdot 1 \mathrm{~kb}$ plasmid from the donor strain of A. baumannii occurred at a frequency of $\sim 3.2 \times 10^{-4}$ (transconjugants : donor). All transconjugants obtained from $A$.

baumannii demonstrated the same plasmid profile, usually similar to that of the donor plasmid profile of $66 \cdot 1 \mathrm{~kb}$ (Fig. 1, lane 2). No significant differences were noted among the patterns of $\beta$-lactam susceptibility of all transconjugants obtained from donor $A$. baumannii isolates (Table 1). Resistance to 
Table 1. MICs of $\beta$-lactams alone and in combination with the $\beta$-lactamase inhibitor clavulanic acid MICs are given in $\mu \mathrm{g} \mathrm{ml}^{-1}$. CLA, Clavulanic acid; SBT, sulbactam.

\begin{tabular}{|c|c|c|c|c|c|}
\hline Antibiotic & A. baumannii & Cured A. baumannii & E. coli DH5 $\alpha$ & E. coli transconjugant & $\begin{array}{l}\text { Cured E. coli } \\
\text { transconjugant }\end{array}$ \\
\hline Ampicillin + SBT & $<8$ & $<8$ & $0 \cdot 125$ & $<0 \cdot 5$ & $<0 \cdot 5$ \\
\hline Amoxycillin & $>512$ & $0 \cdot 5$ & $0 \cdot 5$ & $>512$ & $0 \cdot 5$ \\
\hline Amoxycillin+CLA & $<16$ & $0 \cdot 5$ & $0 \cdot 125$ & $<16$ & $0 \cdot 125$ \\
\hline Cefazolin & $>512$ & $>0 \cdot 125$ & $>0 \cdot 5$ & $>512$ & $>0 \cdot 125$ \\
\hline Cefoperazone & $>512$ & $0 \cdot 5$ & $0 \cdot 125$ & $256-512$ & $0 \cdot 125$ \\
\hline Ceftazidime & $>256$ & $0 \cdot 5$ & $0 \cdot 125$ & 256 & $0 \cdot 125$ \\
\hline Ceftazidime+CLA & $<0 \cdot 5$ & $0 \cdot 5$ & $0 \cdot 125$ & $<0 \cdot 5$ & $0 \cdot 125-0 \cdot 5$ \\
\hline Cefuroxime & $>512$ & $0 \cdot 5$ & $0 \cdot 5$ & $>512$ & $0 \cdot 5$ \\
\hline Cefotaxime & $>256$ & $0 \cdot 125-0 \cdot 5$ & $0 \cdot 125-0 \cdot 5$ & $>256$ & $0 \cdot 5$ \\
\hline Cefotaxime+CLA & $<0 \cdot 5$ & $0 \cdot 125$ & $0 \cdot 125$ & $<0 \cdot 5$ & $0 \cdot 5$ \\
\hline
\end{tabular}

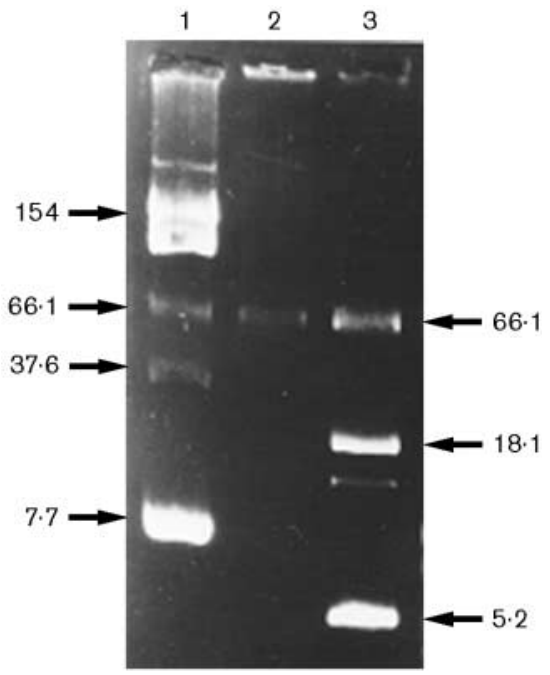

Fig. 1. Plasmid DNA profiles after agarose gel electrophoresis. Lanes: 1, reference plasmids isolated from E. coli MCTC 50192; 2, E. coli DH5 $\alpha$ transconjugant; 3 , A. baumannii clinical isolate. Molecular sizes are in $\mathrm{kb}$.

cefazolin, cefoperazone, cefotaxime and ceftazidime was always co-transferred with plasmid DNA, suggesting that the resistance determinants were carried by the same $66 \cdot 1 \mathrm{~kb}$ conjugative plasmid.

Recently, multiple-antibiotic-resistant $A$. baumannii have been widely reported from ICU (Bergogne-Berezin \& Towner, 1996). In the authors' own hospital, the isolates of A. baumannii reported were predominantly resistant to newer $\beta$-lactams (Joshi, 1998; Joshi et al., 2003). $\beta$-Lactam resistance has been reported in many nosocomial pathogens, including Acinetobacter spp.
(Mulvey et al., 2003), but plasmid-borne transferable ESBL-producing Acinetobacter has not been reported to date. PER-1-type ESBL-producing Acinetobacter spp. have been described (Vahaboglu et al., 2001), but no plasmid-mediated transferability was found. The results of this study confirm the presence of ESBL-producing isolates of $A$. baumannii isolated from ICU. The similar antibiograms, biotypes, specimen types and plasmid profiles of the isolates are highly indicative of clonal spread. A plasmid of $66 \cdot 1 \mathrm{~kb}$ was readily transferred into $E$. coli DH5 $\alpha$ by filter mating with concurrent transfer of ESBL determinants. This demonstrated that the ESBL was plasmidencoded and could be readily spread among other organisms by mere conjugation. The plasmid-borne status of these ESBL determinants was further confirmed by plasmid-curing experiments of donor and E. coli transconjugants and antimicrobial susceptibility and DDS results. We did not characterize the ESBL in detail, but focused only on the transferable nature of ESBL genes carried on a conjugative plasmid. The transconjugation experiments in E. coli $\mathrm{DH} 5 \alpha$ also support the hypothesis that plasmid-borne ESBL genes can be readily disseminated to other nosocomial pathogens. The ESBL activity was inhibited by the $\beta$-lactamase inhibitor clavulanic acid. A significant decrease in MIC of cefotaxime and ceftazidime also confirmed the involvement of ESBL production. Possible spread of resistance markers via conjugative plasmid transfer has been reported (Bergogne-Berezin \& Towner, 1996; Joshi, 1998), but transferable ESBL production has not been reported so far in Acinetobacter spp. Third-generation cephalosporins are widely used in our ICU, but fourth- generation cephalosporins are not readily available. The selective pressure of thirdgeneration $\beta$-lactams would be high and is perhaps responsible for the repeated selection of mutants of resistance determinants (Bergogne-Berezin, 2001).

It is known that ESBL-mediated resistance may increase the basal level of naturally occurring multi-drug resistance among other nosocomial pathogens by dissemination and integration of Rplasmids. Therefore, it is advisable to include $A$. baumannii in screening programmes for ESBL-producing Gramnegative aerobes. Future studies on characterization of the ESBL and the epidemiology of the source of the plasmid in this study are in progress.

Suresh G. Joshi, Geetanjali M. Litake, Vikram S. Ghole and Krishnarao B. Niphadkar

Department of Microbiology, King Edward Memorial Hospital, Rasta Peth, Pune 411 011 India

Correspondence: Suresh G. Joshi (surejoshi@yahoo.com) (present address: Department of Medicine, Box 610, University of Rochester Medical Center, School of Medicine and Dentistry, 601 Elmwood Ave, Rochester, NY 14642, USA)

Bergogne-Berezin, E. (2001). The increasing role of Acinetobacter species as nosocomial pathogens. Curr Infect Dis Rep 3, 440-444.

Bergogne-Berezin, E. \& Towner, K. J. (1996). Acinetobacter spp. as nosocomial pathogens: microbiological, clinical, and epidemiological features. Clin Microbiol Rev 9, 148-165.

Bouvet, P. J. M. \& Grimont, P. A. D. (1987). 
Identification and biotyping of clinical isolates of Acinetobacter. Ann Inst Pasteur Microbiol 138, 569-578.

Dy, M. E., Nord, J. A., LaBombardi, V. J. \& Kislak, J. W. (1999). The emergence of resistant strains of Acinetobacter baumannii: clinical and infection control implications. Infect Control Hosp Epidemiol 20, 565-567.

Jarlier, V., Nicolas, M. H., Fournier, G. \& Philippon, A. (1988). Extended broadspectrum $\beta$-lactamases conferring transferable resistance to newer $\beta$-lactam agents in Enterobacteriaceae: hospital prevalence and susceptibility patterns. Rev Infect Dis 10, 867-878

Joshi, S. G. (1998). Assignment of antibiotic resistance to naturally occurring plasmids from clinical isolates of Acinetobacter species. $\mathrm{PhD}$ thesis, University of Pune, Pune, India.

Joshi, S. G., Litake, G. M., Niphadkar, K. B. \& Ghole, V. S. (2003). Multidrug resistant Acinetobacter baumannii isolates from a teaching hospital. J Infect Chemother $\mathbf{9}$, 187-190.

Levin, A. S., Levy, C. E., Manrique, A. E. I., Medeiros, E. A. S. \& Costa, S. F. (2003). Severe nosocomial infections with imipenemresistant Acinetobacter baumannii treated with ampicillin/sulbactam. Int J Antimicrob Agents $21,58-62$.

Mulvey, M. R., Soule, G., Boyd, D., Demczuk, W. \& Ahmed, R. (2003). Characterization of the first extended-spectrum $\beta$-lactamaseproducing Salmonella isolate identified in Canada. Multi-provincial Salmonella typhimurium Case Control Study Group. J Clin Microbiol 41, 460-462.

NCCLS (1997). Methods for dilution antimicrobial susceptibility tests for bacteria that grow aerobically. Approved Standard M7A4. Villanova, PA: National Committee for Clinical Laboratory Standards.

Perilli, M., Felici, A., Oratore, A., Cornaglia, G., Bonfiglio, G., Rossolini, G. M. \& Amicosante, G. (1996). Characterization of the chromosomal cephalosporinases produced by Acinetobacter lwoffii and Acinetobacter baumannii clinical isolates. Antimicrob Agents Chemother 40, 715-719.

Poirel, L., Karim, A., Mercat, A., Le Thomas, I., Vahaboglu, H., Richard, C. \& Nordmann, P. (1999). Extended-spectrum $\beta$-lactamase- producing strain of Acinetobacter baumannii isolated from a patient in France. J Antimicrob Chemother 43, 157-158.

Sambrook, J., Fritsch, E. F. \& Maniatis, T. (1989). Molecular Cloning: a Laboratory Manual. Cold Spring Harbor, NY: Cold Spring Harbor Laboratory.

Stanisich, V. A. (1988). Identification and analysis of plasmids at the genetic level. Methods Microbiol 21, 11-48.

Vahaboglu, H., Coskunkan, F., Tansel, O. \& 10 other authors (2001). Clinical importance of extended-spectrum $\beta$-lactamase (PER-1type)-producing Acinetobacter spp. and Pseudomonas aeruginosa strains. J Med Microbiol 50, 642-645.

Von Graevenitz, A. (1995). Acinetobacter, Alcaligenes, Moraxella and other nonfermentative gram-negative bacteria. In Manual of Clinical Microbiology, pp. 520-532. Edited by P. J. Murray, E. J. Baron, M. A. Pfaller, F. C. Tenover \& R. H. Yolken. Washington, DC: American Society of Microbiology.

Willets, N. (1988). Conjugation. Methods Microbiol 21, 49-75. 